\title{
Evaluation of the Land Quality in Front and Back Land Consolidation
}

\author{
XIAO Yi ${ }^{1, a}$, YIN Ke $\mathrm{K}^{2, \mathrm{~b}}$
}

\section{College of Tourism and Land Resources; Chongqing Technology and Business University; Chongqing 400067;}

\author{
2. College of Geographical and Travel, Chongqing Normal University, Chongqing 400047

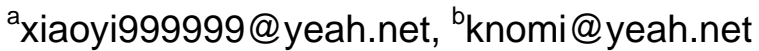

Keywords: Land consolidation; Effects; Hills and mountains

Abstract. The research object of this paper is DaZu comprehensive land consolidation projects in Hechuan County of Chongqing, analysis the land comprehensive consolidation impact on land quality in hills and mountains. The results show: (1)Through comprehensive improvement of rural land, land topography factors increase the value of $20.85 \%$; Soil factors increase the value of 11.58\%; Moisture factors comprehensive values improved8.09\%; Landscape factors increase the value of $1.90 \%$ 。(2)Overall, land quality integrated value is 1 before comprehensive improvement of rural land. Land quality integrated value is 1.4242 after comprehensive improvement of rural land, improved by $42.42 \%$. Visible through the comprehensive improvement of rural land, land quality has increased in the study area, a good foundation for the sustainable development of agriculture.

\section{Introduction}

In recent years, under the principle of building a new socialist countryside guidance, Launched a number of projects to benefit farmers in chongqing. Such as land development and consolidation projects, low-yielding farmland, village project, the construction of a new socialist countryside, etc $[1-3]$

However, under the new rural construction, land consolidation as a carrier to promote the construction of a model village just started, less empirical research on it. To this end, explore comprehensive land management mode under the new countryside construction, improve the planning of democracy, scientific, feasibility is very important ${ }^{[4-6]}$. The research object of this paper is DaZu comprehensive land consolidation projects in Hechuan County of Chongqing, analysis the land comprehensive consolidation impact on land quality in hills and mountains.

\section{Materials and Methods}

Data Sources. The original data mainly comes from DaZu town land use change survey data in 2010, DaZu town 2014 Statistical Yearbook, the author's practical survey, use Hechuan County Planning Bureau, trade and Economic Cooperation Bureau, agriculture bureau and other departments data for supplementary.

Research Methods. Learn from previous research results, combined with the actual situation of the study area, Establish evaluation indictor system of land quality in land improvement area (Tab.1 ${ }^{[7]}$. The quality index value of the default is 1 before land consolidation. Using the following formula standardization:

$$
F=X_{i} / X_{j}
$$

Where: $\mathrm{F}$ is the value of $\mathrm{i}$ indexes after standardization, $\mathrm{Xi}$ is the value $\mathrm{i}$ indexes after the comprehensive improvement, $\mathrm{Xj}$ is the value $\mathrm{i}$ indexes before the comprehensive improvement. Normalized index value, $\mathrm{F}$ is greater than 1 , indicates that the value of land quality indicators improved; $\mathrm{F}$ is equal to 1 , indicating no change in the value of land quality indicators; $\mathrm{F}$ is less than 1 , indicating that the lower value of land quality indicators. 
Tab. 1 Evaluation indictor system of land quality in land improvement area

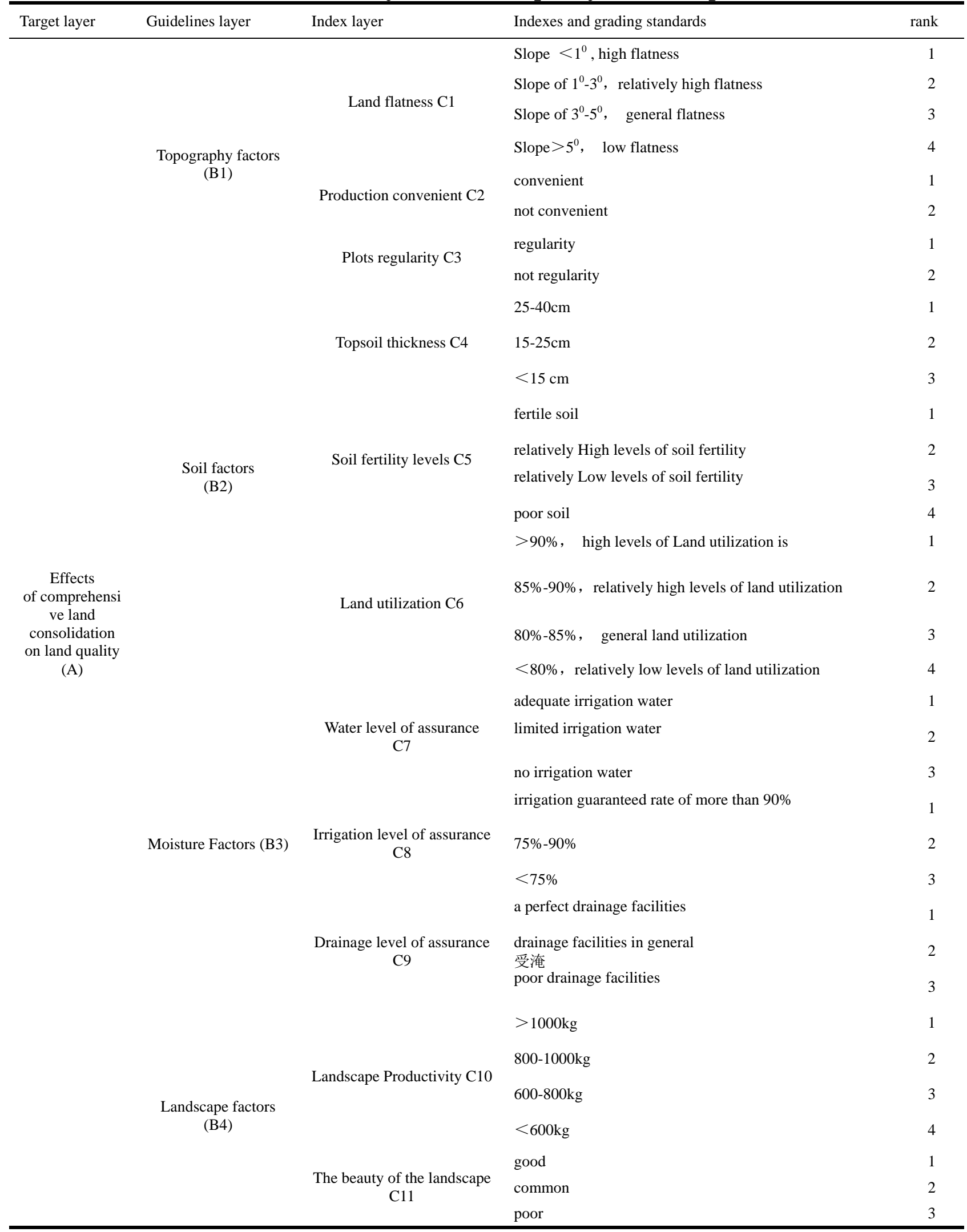

Finally, we use the following formula to calculate the value of the land quality.

$$
E=\sum_{i=1}^{n} F_{i} \times W_{i}
$$

Where: Fi represent the standard value of $\mathrm{i}$ indicators, $\mathrm{E}$ represent comprehensive evaluation value of the land quality, Wi representatives weight of $\mathrm{i}$ indicators. 


\section{Evaluation Results}

The results show that( Tab.2 ) : through comprehensive improvement of rural land, land topography factors increase the value of $20.85 \%$. Among them, land flatness comprehensive values improved $10.27 \%$, production convenient comprehensive values improved $4.88 \%$, plots regularity comprehensive values improved5.70\%; Soil factors increase the value of $11.58 \%$, among them, topsoil thickness comprehensive values improved $4.54 \%$, soil fertility levels comprehensive values improved6.69\%, $\mathrm{n}$ land utilization improved0.35\%; Moisture Factors comprehensive values improved8.09\%, Among them, water level of assurance comprehensive values improved2.98\%, irrigation level of assurance comprehensive values improved3.77\%, drainage level of assurance comprehensive values improved1.34\%; Landscape factors increase the value of $1.90 \%$, among them, landscape productivity comprehensive values improved $1.24 \%$, the beauty of the landscape comprehensive values improved0.66\%。

Tab. 2 The index standard value of land quality

\begin{tabular}{|c|c|c|c|c|c|c|}
\hline Index layer & After remediation & Before remediation & Standard scores & $\begin{array}{l}\text { Comprehensive } \\
\text { value of after } \\
\text { remediation }\end{array}$ & $\begin{array}{c}\text { Comprehensive } \\
\text { value of before } \\
\text { remediation }\end{array}$ & added value \\
\hline C1 & 60 & 90 & 1.50 & 0.2044 & 0.3071 & 0.1027 \\
\hline C2 & 80 & 100 & 1.25 & 0.1053 & 0.1541 & 0.0488 \\
\hline C3 & 60 & 100 & 1.67 & 0.0821 & 0.1391 & 0.057 \\
\hline 小计 & - & - & - & 0.3918 & 0.6003 & 0.2085 \\
\hline C4 & 60 & 90 & 1.50 & 0.0868 & 0.1322 & 0.0454 \\
\hline C5 & 60 & 90 & 1.50 & 0.1148 & 0.1817 & 0.0669 \\
\hline C6 & 100 & 100 & 1.00 & 0.0711 & 0.0746 & 0.0035 \\
\hline 小计 & - & - & - & 0.2727 & 0.3885 & 0.1158 \\
\hline C7 & 80 & 100 & 1.25 & 0.1161 & 0.1459 & 0.0298 \\
\hline C8 & 60 & 100 & 1.67 & 0.0594 & 0.0971 & 0.0377 \\
\hline C9 & 80 & 100 & 1.25 & 0.0413 & 0.0547 & 0.0134 \\
\hline 小计 & - & $\longrightarrow$ & - & 0.2168 & 0.2977 & 0.0809 \\
\hline C10 & 80 & 90 & 1.13 & 0.0604 & 0.0728 & 0.0124 \\
\hline C11 & 60 & 90 & 1.50 & 0.0583 & 0.0649 & 0.0066 \\
\hline 小计 & - & - & - & 0.1187 & 0.1377 & 0.019 \\
\hline total & - & - & - & 1 & 1.4242 & 0.4242 \\
\hline
\end{tabular}

Overall, Land quality integrated value is 1 before Comprehensive improvement of rural land, Land quality integrated value is 1.4242 after Comprehensive improvement of rural land, improved by $42.42 \%$. Visible through the comprehensive improvement of rural land, land quality has increased in the study area, a good foundation for the sustainable development of agriculture. However, due to the qualitative evaluation described in more in the study, assignment method is more simple, there is a strong subjective and the result accuracy is not high. Future studies, can make use of mathematical methods and modern techniques, establish comprehensive land quality evaluation method more suitable for the comprehensive improvement of rural land.

\section{Conclusion}

The research object of this paper is DaZu comprehensive land consolidation projects in Hechuan County of Chongqing, analysis the land comprehensive consolidation impact on regional land quality. The conclusion is as follows: 
(1)Through comprehensive improvement of rural land, land topography factors increase the value of $20.85 \%$; Soil factors increase the value of $11.58 \%$; Moisture factors comprehensive values improved $8.09 \%$; Landscape factors increase the value of $1.90 \%$ 。

(2)Overall, land quality integrated value is 1 before comprehensive improvement of rural land, Land quality integrated value is 1.4242 after comprehensive improvement of rural land, improved by42.42\%. Visible through the comprehensive improvement of rural land, land quality has increased in the study area, a good foundation for the sustainable development of agriculture.

However, due to the qualitative evaluation described in more in the study, assignment method is more simple, there is a strong subjective and the result accuracy is not high. Future studies, can make use of mathematical methods and modern techniques, establish comprehensive land quality evaluation method more suitable for the comprehensive improvement of rural land.

\section{Acknowledgements}

This work was financially supported by the National Natural Science Foundation of China (41301654; 41201597). This work was financially supported by the Chongqing Technology and Business University Science Start Foundation of China（2013-56-07）.

\section{References}

[1] Chen Liding, Wang Jun, Fu Bojie. Land use change in a small catchments of northern loess plateau china[J]. Agriculture, Ecosystem and Environment. 86(2), 163-172(2001)

[2]Xiaojun Liao; Improvement benefiting the agriculture policy of strong support for the modernization of specialty agriculture China, Chinese fiscal, 3(10), 8 -11 (2008).

[3]Zhang T W. Land market forces and government's role in sprawl: the case of China [J]. Cities, 17 (2),123- 135(2000).

[4]Petr S; Applying evaluation criteria for the land consolidation effect to three contrasting study areas in the Czech Republic, Land Use Policy, 23 (4), 502-510 (2006).

[5]David M,Rafael C,Flora M; Land consolidation in inland rural Galicia,N.W, Spain,since 1950:An example of the formulation and use of questions, criteria and indicators for evaluation of rural, Land Use Policy, 23 (4), 511-520 (2006).

[6]Bonfant P. Landscape analysis in areas affected by land consolidation, Landscape and Urban Planning, 37(l), 91-98 (1997).

[7]Miller W, Collins W M G, Steiner F R, et al. An approach for green way suitability analysis [J]. Landscape and Urban Planning, 11(42), 91-105(1998). 